\title{
The anti-cataract molecular mechanism study in selenium cataract rats for baicalin ophthalmic nanoparticles
}

This article was published in the following Dove Press journal:

Drug Design, Development and Therapy

\author{
Nan $\mathrm{Li}^{1-3, *}$ \\ Zhenzhen Han ${ }^{1,2,4, *}$ \\ Lin $\mathrm{Li}^{1,2}$ \\ Bing Zhang ${ }^{1-3}$ \\ Zhidong Liul-3 \\ Jiawei $\mathrm{Li}^{1,2}$
}

'Tianjin State Key Laboratory of Modern Chinese Medicine, Tianjin University of Traditional Chinese Medicine,Tianjin, People's Republic of China; ${ }^{2}$ Institute of Traditional Chinese Medicine, Tianjin University of Traditional Chinese Medicine, Tianjin, People's Republic of China; ${ }^{3}$ Engineering Research Center of Modern Chinese Medicine Discovery and Preparation Technique, Ministry of Education, Tianjin University of Traditional Chinese Medicine, Tianjin, People's Republic of China; ${ }^{4}$ Baokang Hospital, Tianjin University of Traditional Chinese Medicine, Tianjin, People's Republic of China

*These authors contributed equally to this work

\begin{abstract}
Purpose: The objective of this study was to investigate the effects of the solid lipid nanoparticles of baicalin (BA-SLNs) on an experimental cataract model and explore the molecular mechanism combined with bioinformatics analysis.
\end{abstract}

Materials and methods: The transparency of lens was observed daily by slit-lamp and photography. Lenticular opacity was graded. Two-dimensional gel electrophoresis (2-DE) was employed to analyze the differential protein expression modes in each group. Proteins of interest were subjected to protein identification by nano-liquid chromatography tandem mass spectrometry (LC-MS/ MS). Bioinformatics analysis was performed using the Ingenuity Pathway Analysis (IPA) online software to comprehend the biological implications of the proteins identified by proteomics.

Results: At the end of the sodium selenite-induced cataract progression, almost all lenses from the model group developed partial nuclear opacity; however, all lenses were clear and normal in the blank group. There was no significant difference between the BA-SLNs group and the blank group. Many protein spots were differently expressed in 2-DE patterns of total proteins of lenses from each group, and 65 highly different protein spots were selected to be identified between the BA-SLNs group and the model group. A total of 23 proteins were identified, and 12 of which were crystalline proteins.

Conclusion: We considered crystalline proteins to play important roles in preserving the normal expression levels of proteins and the transparency of lenses. The general trend in the BA-SLN-treated lenses' data showed that BA-SLNs regulated the protein expression mode of cataract lenses to normal lenses. Our findings suggest that BA-SLNs may be a potential therapeutic agent in treating cataract by regulating protein expression and may also be a strong candidate for future clinical research.

Keywords: BA-SLNs, 2-DE patterns, nano-LC-MS/MS, IPA, SDS-PAGE

\section{Introduction}

Cataract, characterized by opacification or optical dysfunction of the lens, has been a leading cause of blindness worldwide. It usually develops very slowly and gradually with age. A report by World Health Organization shows that the total number of persons with cataracts is estimated to rise to 30.1 million by 2020, and it differs from country to country. ${ }^{1}$ Cataract has become a disease starving for treatment. Various studies have confirmed that multiple risk factors such as diet, diabetes, daylight, dehydration, oxidation of lens proteins, and peroxidation of lipids influence the generation of lens opacities in older individuals. ${ }^{2}$ Among the various causes, oxidative stress is considered to play a key role in the molecular mechanism of cataract formation. ${ }^{3}$ Oxidative stress occurs when the level of pro-oxidants surpasses the level of antioxidants. Free radicals, including
Correspondence: Zhidong Liu; Jiawei Li Engineering Research Center of Modern Chinese Medicine Discovery and Preparation Technique, Ministry of Education, Tianjin University of Traditional Chinese Medicine, No 88 Yuquan Road, Tianjin 300193, People's Republic of China

Tel +86225959 6170; +862259596294

Fax +862227412619

Email lonerliuzd@।63.com;

lijiaweil98I@163.com
Drug Design, Development and Therapy 2018:12 |399-14||

(c) (1) (2) ๑ 2018 Li et al. This work is published and licensed by Dove Medical Press Limited. The full terms of this license are available at https//wwr.dovepress.com/terms.php

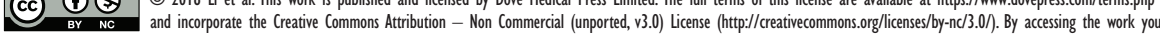
hereby accept the Terms. Non-commercial uses of the work are permitted without any further permission from Dove Medical Press Limited, provided the work is properly attributed. For permision for commercial use of this work, please see paragraphs 4.2 and 5 of our Terms (https://www.dovepress. com/terms.php). 
numerous reactive oxygen species (ROS) such as superoxide anion radical, $\mathrm{H}_{2} \mathrm{O}_{2}$, and hydroxyl free radical, may affect the structure and function of the lens, modulate aggregation of the lens, and contribute to cataract formation. ${ }^{4}$ Excessive free radical generation leading to oxidative stress has been identified as one of the major triggering factors for senile cataract formation. ${ }^{5}$ As a result, efforts have been taken to develop an effective antioxidant treatment, both of synthetic and plant origins in delaying the onset and the progression of cataract. ${ }^{6}$

Baicalin (5,6,7-trihydroxyflavone-7- $\beta$-D-glucuronide) is a major flavonoid derived from the root of Scutellaria baicalensis Georgi (Scutellariae Radix). A series of studies have proven that it is an effective antioxidant, antiviral, anti-inflammatory, antitumor, ${ }^{7}$ etc. ${ }^{50-52}$ Flavonoids, found in various foods and beverages, have strong anti-cataract and antioxidant activities. ${ }^{8}$ In recent years, solid lipid nanoparticles (SLNs) have been proposed as a new ophthalmic delivery system, which can enhance residence time on the ocular surface and improve the bioavailability of drugs. ${ }^{9}$ In our recent study, SLNs of baicalin (BA-SLNs) ${ }^{10}$ and reported it as an efficient ROS scavenger upregulating glutathione (GSH) level and superoxide dismutase (SOD) activity in a BA-SLNs' treatment group of sodium selenite-induced cataractic rats. ${ }^{11}$ With its quick and reproducible properties, the seleniteinduced cataract model has been commonly used for studying the mechanism of age-related cataract formation. Recent works on baicalin have also provided several interesting new findings, relevant to our current study. Zhao et al ${ }^{12}$ reported that mice fed with a baicalin-containing diet for 50 days showed an increased antioxidative status and decreased iron content and lipid peroxidation in the liver after iron overload. We therefore considered BA-SLNs to be a potentially useful antioxidant and anti-cataract agent. At present, there is no reported study on the antioxidant properties of BA-SLNs with regard to cataract formation. Therefore, we proceeded to find out the molecular mechanism of the anti-cataract effect of this novel baicalin ophthalmic preparation.

With the progress in proteomic analysis, proteomic approaches have been applied to identify proteins in various physiological or pathological conditions in organelles, cells, organisms, and extracellular body fluids. ${ }^{13-15}$ Twodimensional gel electrophoresis (2-DE) has been a classic method of preparation of microanalytical amounts of starting material for protein analysis. Mass spectrometry (MS), a powerful tool, has also been used to successfully identify proteins. Researchers have used this method to analyze the proteome of cataractic or normal lenses. ${ }^{16,17}$ Thus, we applied this method to investigate the effect of BA-SLNs on the proteome of cataractic lens. Differential expression patterns of the lens proteome with or without administration of BA-SLNs were obtained by employing 2-DE. Protein spots that showed \pm 2 -fold different protein expressions between the two conditions were then subjected to nano-liquid chromatography tandem mass spectrometry (LC-MS/MS) and the identity of the proteins was obtained. Bioinformatics was performed to comprehend the biological implications of the proteins identified by proteomics. Ingenuity pathway analysis (IPA) was used to analyze the data. To the best of our knowledge, this is the first report that looks into the differential proteomic profile of cataract in response to BA-SLNs' treatment. This study could serve as a basis for further clinical investigations.

\section{Materials and methods Materials}

Immobilized Ph gradient (IPG) gel strip (Bio-Rad Laboratories Inc., Hercules, CA, USA), 3-[(3-cholamidopropyl) dimethylammonio] propanesulfonic acid (CHAPS) (SigmaAldrich Co., St Louis, MO, USA), urea (Sangon Biotech Co.,Ltd, Shanghai, People's Republic of China), iodoacetamide (Sigma-Aldrich Co.), thiourea (Tianjin Chemical Reagent Factory, Tianjin, People's Republic of China), PH3-10 ampholytes (Bio-Rad Laboratories Inc.), phenylmethanesulfonyl fluoride (PMSF) (Sigma-Aldrich Co.), acetonitrile (ACN) (Thermo Fisher Scientific, Waltham, MA, USA), dithiothreitol (DTT) (Merck Millipore, Billerica, MA, USA), iodoacetamide (Aladdin), formic acid (Alfa Aesar, shanghai, People's Republic of China), trypsin solution (purified by the laboratory), and baicalin ( $>98 \%$; Zhong Xin Pharmaceuticals, Tianjin, China) were used. Soya phospholipids SL-100 was acquired from Lipoid (Rheinland-Pfalz, Ludwigshafen, Germany). Poloxamer 188 was obtained from BASF (Deutschland, Ludwigshafen, Germany). Triglyceride was purchased from Tianjin North Tianyi Chemical Agent Factory, Tianjin, People's Republic of China. All other chemicals and reagents were of analytical grade.

\section{Animals}

Wistar rat pups (aged 9 days) were supplied by Institute of Radiation Medicine, Chinese Academy of Medical Sciences and Peking Union Medical College, China. The animals were housed in a temperature-controlled room with a $12 \mathrm{~h}$ light and dark cycle and provided with free access to water and food. All studies were conducted in accordance with the Principles of Laboratory Animal Care (NIH publication no 92-93, revised in 1985) and were approved by the Department of Laboratory Animal Research at the Tianjin University of Traditional Chinese Medicine. All experiments were performed with approval from the Laboratory Animal Ethics Committee of Tianjin University 
of Traditional Chinese Medicine (approval number TCMLAEC2013010). The rats were acclimatized for a period of 3 days in the new environment before the initiation of the experiment. Efforts were made to minimize animals suffering.

\section{Drug administration and induction of cataract}

Cataract rat model was induced with sodium selenite according to a previously reported method (Shearer et al, 1997; Elanchezhian et al, 2009) with a minor modification. ${ }^{5,18}$ Briefly, rat pups were randomly separated into blank, control, and treatment groups $(n=10)$. At 12 days of age (20-25 g), before opening of their eyelids, the control and treatment groups received a single subcutaneous injection of sodium selenite ( $25 \mu \mathrm{mol} / \mathrm{kg}$ ), whereas the blank group received saline. Then, $20 \mu \mathrm{L}$ of $0.1 \%$ BA-SLNs as eye drops was given to the treatment group, meanwhile same volume of saline was given to the blank and control groups. Drug was administered three times a day for 4 days. Changes in the lens were observed daily by slit-lamp (YZ2, Suzhou, China) and photography. Lenticular opacity was graded as described by Hiraoka and Clark. ${ }^{19}$ At the end of 4 days, the rat pups were sacrificed by cervical dislocation. Their lenses were severed from the eyes leaving the lens capsule intact and stored at $-80^{\circ} \mathrm{C}$ until required.

\section{Preparation of protein for electrophoretic analysis}

The lenses in every group were homogenized by ultrasound disintegration on ice for $10 \mathrm{~s}$ per $0.5 \mathrm{~s}$ interval in lysate containing $8 \mathrm{M}$ urea, $2 \mathrm{M}$ thiourea, $2 \%$ CHAPS, $2 \%$ ampholytes, $1 \%$ DTT, and $1 \mathrm{mM}$ PMSF with $50 \mathrm{mM}$ deoxyribonuclease I (Dnase I). Proteins were obtained from the supernatant by centrifugation at $12,000 \mathrm{rpm}$ for $30 \mathrm{~min}$ at $4^{\circ} \mathrm{C}$ and frozen at $-80^{\circ} \mathrm{C}$ prior to analysis.

\section{Two-dimensional gel electrophoresis}

The protein concentration was measured by the Bradford method with the loading quantity being $0.8 \mathrm{mg}$ per sample from each of the three groups. 2-DE was performed with a horizontal isoelectric focusing (IEF) system (Multiphor II, Amersham Bioscience, USA), using precast immobilized linear-gradient (IPG, pH 3-10) strips for the first dimension, and $12 \%$ sodium dodecyl sulfate-polyacrylamide gel electrophoresis (SDS-PAGE) for the second dimension. The SDS-PAGE was run in a Multi-Gel Casting Chamber (BioRad Laboratories Inc.). Initially, IPG gel strip was rehydrated in buffer ( $8 \mathrm{M}$ urea, $2 \mathrm{M}$ thiourea, 0.5\% CHAPS, 0.52\% ampholytes, $0.02 \%$ bromophenol blue, $1 \% \mathrm{DTT}$ ) for $12 \mathrm{~h}$ and IEF performed with the following voltage program: 0-500 V (rapid for $500 \mathrm{~V} \cdot \mathrm{h}$ ), $500 \mathrm{~V}$ (linear $>2,500 \mathrm{~V} \cdot \mathrm{h}$ ), 500-3,500 V (rapid for $10,000 \mathrm{~V} \cdot \mathrm{h}$ ), 3,500 V (linear $>50,000 \mathrm{~V} \cdot \mathrm{h}$ ), and 3,500-500 V (rapid for 8,000 V·h). Focused IPG strips were equilibrated for $15 \mathrm{~min}$ with equilibration buffer-I $(50 \mathrm{mM}$ Tris-HCl [pH 6.8], $6 \mathrm{M}$ urea, 30\% [v/v] glycerol, $0.02 \%$ bromophenol blue, $2 \%$ SDS, $2 \%$ [w/v] DTT) and $15 \mathrm{~min}$ with equilibration buffer-II (50 mM Tris- $\mathrm{HCl}$ [pH 6.8], $6 \mathrm{M}$ urea, $30 \%$ [v/v] glycerol, $0.02 \%$ bromophenol blue, $2 \%$ SDS, $2.5 \%$ $[\mathrm{w} / \mathrm{v}]$ iodoacedamide). The second-dimensional SDS-PAGE with a $12 \%$ running gel was performed first at a constant current of $15 \mathrm{~mA} / \mathrm{gel}$ for $15 \mathrm{~min}$ and then at $250 \mathrm{~V} /$ gel till the bromophenol blue reached the bottom of the gel. After electrophoresis, the gels were stained with staining buffer (0.12\% Coomassie brilliant blue G-250, 10\% ammonium sulfate, $10 \%$ phosphoric acid, 20\% methanol) overnight. After being destained, images were obtained using UMAX Powerlook 2100XL (UMAX, Taipei, China) at a resolution of 300 dpi and analyzed using the PDQuest 8.0.1 software (BioRad Laboratories Inc.). Protein spot expression levels were analyzed as follows: protein spots from each gel were detected and matched automatically to generate a master gel image from the matched gel sets. Data were exported to Microsoft Excel (Microsoft Corporation, Redmond, WA, USA) for creating correction and spot intensity graphs. Finally, the intensity of the spots was compared between gels.

\section{Nano-LC-MS/MS analysis and database searching}

Gel pieces of interest were excised from gels, rinsed by Milli-Q water three times, and then destained with $50 \mathrm{mM}$ $\mathrm{NaHCO}_{3}, 50 \%$ ACN until completely destained. The destained gel pieces were washed with $100 \%$ ACN and then dried. Reduction and alkylation in $10 \mathrm{mM}$ DTT and $50 \mathrm{mM}$ iodoacetamide, respectively, were followed by washing with $25 \mathrm{mM} \mathrm{NaHCO}_{3}$ twice and then with $25 \mathrm{mM} \mathrm{NaHCO}_{3}$ in $50 \%$ ACN solution also twice and then dried. The dried gel pieces were rehydrated with $10 \mu \mathrm{L}$ of trypsin solution $(20 \mu \mathrm{g} / \mathrm{mL})$ for $10 \mathrm{~min}$ at $4^{\circ} \mathrm{C}$. After the addition of $25 \mathrm{mM}$ $\mathrm{NH}_{4} \mathrm{HCO}_{3}$, the samples were incubated at $37^{\circ} \mathrm{C}$ overnight. Following enzymatic digestion, peptides were triple extracted from the gel using $25 \mu \mathrm{L}$ of extraction buffer and the supernatants were combined. All peptide digestion mixtures were dried and dissolved in sample buffer $(0.1 \%$ formic acid in $5 \% \mathrm{ACN})$. Solvents for nano-LC-MS/MS separation of the digested samples were as follows: solvent A consisted of $0.1 \%$ formic acid in water and solvent B consisted of $0.1 \%$ formic acid in ACN. The peptides were eluted from the analytical column (CTICAP5150100; Column Technology Inc., USA), at a flow rate of $2 \mu \mathrm{L} / \mathrm{min}$ equilibrating with 
$5 \%$ of solvent B for $15 \mathrm{~ms}$, followed by a $45 \mathrm{~ms}$ gradient from 5 to $32 \%$ of solvent B, then to $90 \%$ solvent B within $35 \mathrm{~ms}$, and to $5 \%$ solvent B within $5 \mathrm{~ms}$ and, finally, maintained for $20 \mathrm{~ms}$. For protein identification, nano-LC-MS/ MS analysis was conducted using LTQ XL (Thermo Fisher Scientific) (electrospray ionization tandem MS [ESI-MS/ MS]). The instrument was operated with a spray voltage of $3.5 \mathrm{kV}$ and an ion transfer tube temperature of $250^{\circ} \mathrm{C}$. The information-dependent acquisition (IDA) mode of operation was employed, in which a survey scan from $\mathrm{m} / \mathrm{z} 400$ to 1,800 was acquired, followed by collision-induced dissociation (CID). Normalized collision energy of $35 \%$ with an activation $q$ of 0.25 for $30 \mathrm{~ms}$ was used for the MS/MS. Ion selection thresholds for MS and MS/MS were 1,000 and 500 counts, respectively. Regarding protein search algorithm for peptide mass identification, tandem mass spectra were extracted by Xcalibur Version 1.0.0.2. All MS/MS samples were analyzed using Sequest. Iodoacetamide derivative of Cys, deamidation of Asn and Gln, and oxidation of Met were specified in Sequest as variable modifications. MS/MS-based peptides and proteins were retrieved from rat.fasta from NCBI database using the Proteome Discoverer 1.2 software.

Proteome Discoverer 1.2 was used to validate MS/MSbased peptide and protein identification. Peptide identification was accepted if they could be established at $>95.0 \%$ probability as specified by the result filter, where Xcorr $>1.9$ if Charge $=1$, Xcorr $>2.2$ if Charge $=2$, and Xcorr $>3.75$ if Charge $=3$. Protein identification was also accepted if established at $>99.0 \%$ probability and contains at least two identified unique peptides.

\section{Bioinformatic analysis of biological networks}

Gene Ontology annotation, pathways, and protein interaction network analysis were performed to comprehend the biological implications of proteins identified by proteomics using the IPA online software.

\section{Statistical analysis}

Differences in protein spots' content between the BA-SLNs and model groups were analyzed using a test $(n=3)$, only those with \pm 2 -fold expressed change were considered as significantly differentially expressed proteins when comparing BA-SLNs group with model group. Gene Ontology annotation, pathway, and network analysis were performed to elaborate the interaction of proteins identified by proteomics.

\section{Results \\ Effect of BA-SLNs on sodium selenite- induced cataract progression}

Lens transparency was observed daily. After 4 days, Stage 4 cataract formation (partial nuclear opacity) was observed in almost all lenses in the model group (Stage 4, Figure 1A). However, all lenses were clear and normal in the blank group (Stage 0, Figure 1B). In the BA-SLNs group, the lenses displayed early posterior subcapsular cataract or minimal nuclear opacity (Stage 1, Figure 1C) and there was no significant difference between the BA-SLNs group and the blank group. The result suggested that the progression of cataract due to sodium selenite-induced oxidative stress, from onset through maturation, was delayed in the group, which received $0.1 \%$ BA-SLNs.

\section{Effect of BA-SLNs on protein expression}

DE patterns of total proteins of lenses from each group were obtained by imaging. Comparative 2-DE-based proteomic analysis was performed between gels. As shown in the images (Figure 2), the proteins varied between 20 and $100 \mathrm{kDa}$ in size and had isoelectric point ( $\mathrm{pI}$ ) values ranging from 4 to 8. Comparing the intensity of the spots $( \pm 2$-fold expressed change), 134 protein spots were differentially expressed between the blank and the model groups, indicating that sodium selenite influences protein expression in lenses to induce cataract. There were 144 and 119 protein spots that
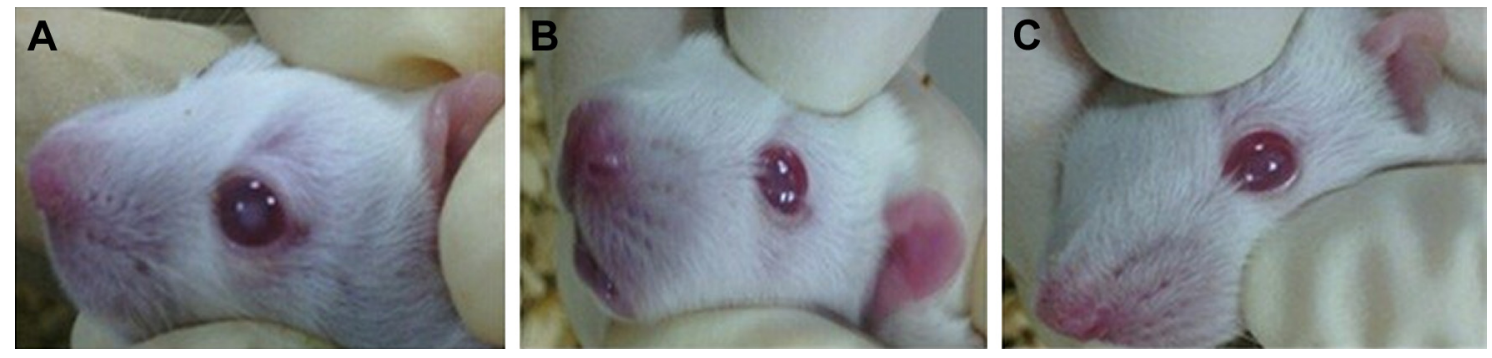

Figure I Cataract formation in three groups.

Notes: (A) Model group (Stage 4 cataract). (B) Blank group (Stage 0 cataract). (C) BA-SLNs group (Stage I cataract).

Abbreviation: BA-SLNs, solid lipid nanoparticles of baicalin. 
A

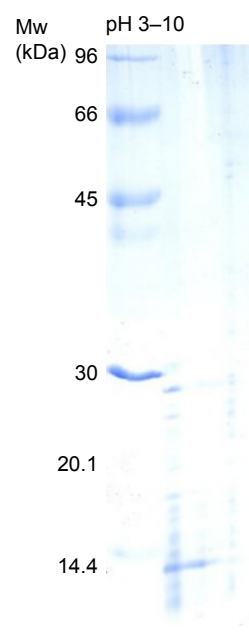

B

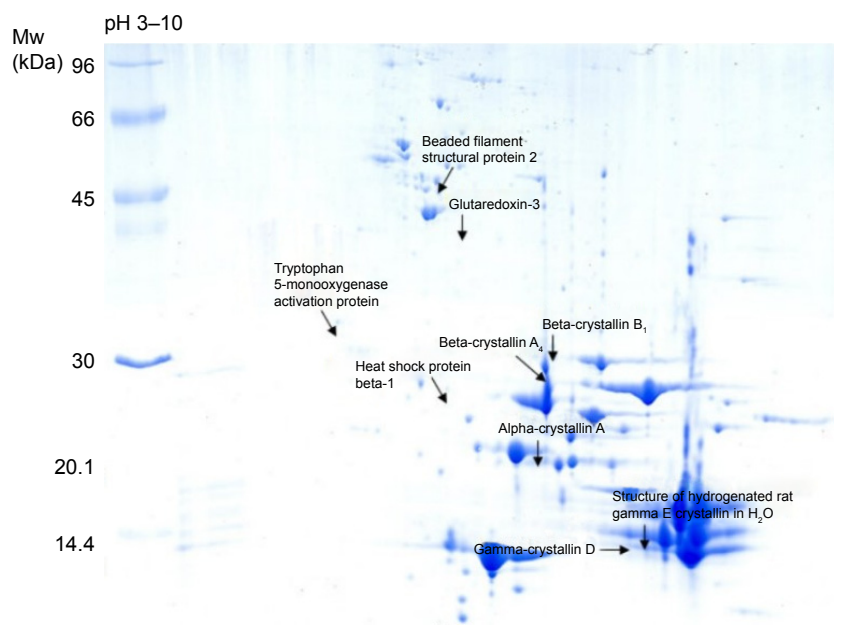

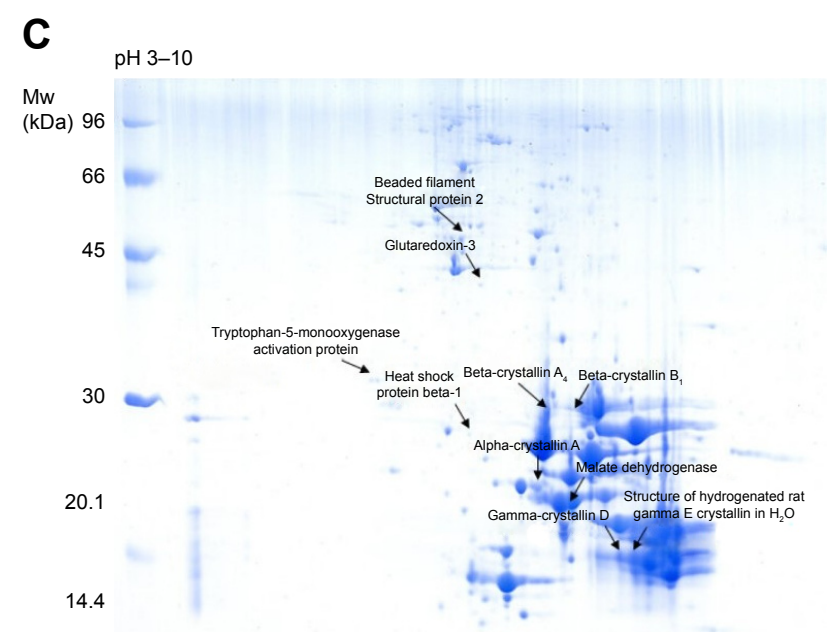

Figure 2 Two dimensional gel images from lenses of three groups.

Notes: Arrows indicate differently expressed protein spots that were identified using nano-LC-MS/MS. (A) Model group. (B) Blank group. (C) BA-SLNs group. Abbreviations: BA-SLNs, solid lipid nanoparticles of baicalin; LC-MS/MS, liquid chromatography tandem mass spectrometry.

were differentially expressed, comparing the BA-SLNs group with the model and the blank groups respectively. Therefore, we concluded that BA-SLNs targeted some proteins and regulated their expression level to delay cataract progression. Considering the limitation of 2-DE and the significance of proteins, we selected 65 protein spots that were differentially expressed between the BA-SLNs and the model groups but similarly expressed between the BA-SLNs and the blank groups. These protein spots were unequivocally identified by peptide mass fingerprinting (PMF). The results were validated by the Proteome Discoverer 1.2 software and were evaluated and determined based on scores, numbers of matched segments, and cover ratio in combination with the molecular mass and isoelectric point (pI) of the protein spot on 2-DE. A total of 23 proteins have been identified from the 65 differentially expressed proteins including vimentin, tryptophan 5-monooxygenase activation protein, tubulin beta- 5 chain, beaded filament structural protein 2 , beaded filament structural protein 1 , heat shock protein beta-1, glutaredoxin-3, serine-tRNA ligase, elongation factor-1 alpha, malate dehydrogenase 1, alpha-crystallin A, alpha-crystallin B, beta-crystallin A4, beta-crystallin $\mathrm{A} 1$, beta-crystallin $\mathrm{B} 1$, beta-crystallin $\mathrm{B} 2$, betacrystallin B3, gamma-crystallin A, gamma-crystallin B, gamma-crystallin C, gamma-crystallin $\mathrm{F}$, gamma-crystallin $\mathrm{D}$, and hydrogenated rat gamma $\mathrm{E}$ crystallin. Their characteristics are shown in Table 1 with distributions indicated by the arrows (Figure 2). Of these, 12 proteins were upregulated and 11 proteins were downregulated in sodium seleniteinduced rat lens. Comparing the intensity of each protein in the model group with the blank group, upregulated proteins were 12 , which include eight crystalline proteins. We therefore considered crystalline protein to play an important role in preserving the normal expression level of proteins and 
Table I Characteristics of identified proteins using nano-LC-MS/MS

\begin{tabular}{|c|c|c|c|c|c|}
\hline Proteins & Score & Peptides & Accession & Description & $\mathbf{P I} / \mathbf{M r}$ \\
\hline I & 458.73 & 32 & gil 4389299 & Vimentin & $5.12 / 53.7$ \\
\hline 2 & 313.34 & 18 & gi38648857 & Tryptophan 5-monooxygenase activation protein & $4.74 / 29.2$ \\
\hline 3 & 591.35 & 24 & gi27465535 & Tubulin beta- 5 chain & $4.89 / 49.6$ \\
\hline 4 & $\mathrm{I}, 22 \mathrm{I} .53$ & 32 & gi476007854 & Beaded filament structural protein 2 & $5.39 / 45.7$ \\
\hline 5 & 71.78 & 9 & gil58|86655 & Beaded filament structural protein I & $6.01 / 73.0$ \\
\hline 6 & 118.26 & 8 & gi94400790 & Heat shock protein beta-I & $6.55 / 22.8$ \\
\hline 7 & 211.70 & 16 & gi78187979 & Glutaredoxin-3 & $5.72 / 37.8$ \\
\hline 8 & 248.08 & 21 & gi56090265 & Serine-tRNA ligase & $6.19 / 58.6$ \\
\hline 9 & 321.36 & 13 & gil 220484 & Elongation factor-I alpha & $9.01 / 50.1$ \\
\hline 10 & 58.98 & 7 & gil5100179 & Malate dehydrogenase I & $6.58 / 36.5$ \\
\hline II & 642.98 & 12 & gil 9526477 & Alpha-crystallin A & $6.20 / 19.8$ \\
\hline 12 & 164.2 & 9 & gi I 3162243 & Alpha-crystallin B & $6.81 / 19.6$ \\
\hline 13 & 991.24 & 9 & gil 3928956 & Beta-crystallin $\mathrm{A}_{4}$ & $6.37 / 22.4$ \\
\hline 14 & 274.74 & 13 & gi40276665। & Beta-crystallin $A_{1}$ & $6.62 / 25.3$ \\
\hline 15 & 465.73 & 16 & gi97392I7 & Beta-crystallin $B_{1}$ & $7.30 / 27.6$ \\
\hline 16 & 24.14 & 18 & gi3891676 & Beta-crystallin $\mathrm{B}_{2}$ & $6.80 / 20.1$ \\
\hline 17 & $1,004.89$ & 13 & gi66774108 & Beta-crystallin $\mathrm{B}_{3}$ & $7.58 / 24.3$ \\
\hline 18 & 644.83 & 10 & gil 49045973 & Gamma-crystallin A & $8.92 / 41.5$ \\
\hline 19 & 423.55 & 10 & gil 58I 38485 & Gamma-crystallin B & $7.62 / 21.1$ \\
\hline 20 & 239.81 & II & gil 26090735 & Gamma-crystallin C & $7.63 / 20.9$ \\
\hline 21 & 578.98 & 10 & gil I 7472 & Gamma-crystallin F & $7.52 / 21.3$ \\
\hline 22 & 555.58 & 7 & gi $1486 \mid 862$ & Gamma-crystallin D & $7.37 / 21.1$ \\
\hline 23 & 286.99 & 8 & gi83753818 & Hydrogenated rat gamma E crystallin & $7.50 / 21.1$ \\
\hline
\end{tabular}

Abbreviations: LC-MS/MS, liquid chromatography tandem mass spectrometry; $\mathrm{PI} / \mathrm{Mr}$, isoelectric point/molecular weight.

the transparency of the lens. The BA-SLN-treated lenses' data showed a general trend that BA-SLNs regulated the protein expression mode from cataract to normal lens protein expression. The 12 upregulated proteins were downregulated by BA-SLNs to normal degrees, while the 11 downregulated proteins were upregulated by this drug. We therefore concluded that BA-SLNs can delay cataract progression by regulating protein expression.

\section{Bioinformatics analysis}

Compared with the model group of sodium selenite-induced cataract rat, BA-SLNs could reverse the abnormal level of 23 proteins and then import these proteins into the IPA software for pathway and network analysis, 22 differentially expressed proteins were mapped (Table 2). The top canonical pathways of these proteins were 14-3-3-mediated signaling, aldosterone signaling in epithelial cells, protein ubiquitination pathway, aspartate degradation II, selenocysteine biosynthesis II (Archaea and Eukaryotes), etc; the result is shown in Figure 3A and B. To further investigate the relative disease and bio-functions among the altered proteins and explore the main proteins of BA-SLNs against sodium selenite-induced cataract rat, bioinformatics analysis showed that these reversed proteins was most relative with developmental disorder, ophthalmic disease, and organismal injury
Table 2 The identified homologous of 22 query proteins with blastp against the rat protein database

\begin{tabular}{|c|c|c|c|}
\hline Proteins & Accession & Description & Symbol \\
\hline $\mathrm{I}$ & gil 4389299 & Vimentin & VIM \\
\hline 2 & gi38648857 & $\begin{array}{l}\text { Tryptophan } \\
\text { 5-monooxygenase } \\
\text { activation protein }\end{array}$ & YWHAE \\
\hline 3 & gi274665535 & Tubulin beta- 5 chain & TUBB \\
\hline 4 & gi476007854 & $\begin{array}{l}\text { Beaded filament structural } \\
\text { protein } 2\end{array}$ & BFSP2 \\
\hline 5 & gil 58186655 & $\begin{array}{l}\text { Beaded filament structural } \\
\text { protein I }\end{array}$ & BFSPI \\
\hline 6 & gi944000790 & Heat shock protein beta-I & HSPBI \\
\hline 7 & gi78187979 & Glutaredoxin-3 & GLRX3 \\
\hline 8 & gi56090265 & Serine-tRNA ligase & SARS \\
\hline 9 & gil 220484 & $\begin{array}{l}\text { Eukaryotic translation } \\
\text { elongation factor I alpha I }\end{array}$ & EEFIAI \\
\hline 10 & gil5100179 & Malate dehydrogenase I & $\mathrm{MDHI}$ \\
\hline 11 & gil 9526477 & Alpha-crystallin A & $\begin{array}{l}\text { CRYAA/ } \\
\text { LOCI02724652 }\end{array}$ \\
\hline 12 & gil 3162243 & Alpha-crystallin B & CRYAB \\
\hline 13 & gil 3928956 & Beta-crystallin $A_{4}$ & CRYBA4 \\
\hline 14 & gi40276665I & Beta-crystallin $A_{1}$ & CRYBAI \\
\hline 15 & gi9739217 & Beta-crystallin $B_{1}$ & CRYBBI \\
\hline 16 & gi3891676 & Beta-crystallin $B_{2}$ & CRYBB2 \\
\hline 17 & gi667744108 & Beta-crystallin $B_{3}$ & CRYBB3 \\
\hline 18 & gi I 49045973 & Gamma-crystallin A & CRYGA \\
\hline 19 & gil $58 \mid 38485$ & Gamma-crystallin B & CRYGB \\
\hline 20 & gil 26090735 & Gamma-crystallin C & CRYGC \\
\hline 21 & gil I 7472 & Gamma-crystallin F & Cryge/Crygf \\
\hline 22 & gil $486 \mid 862$ & Gamma-crystallin D & CRYGD \\
\hline
\end{tabular}


and abnormalities; its molecular and cellular functions were associated with cell death and survival, post-translational modification, and protein folding, and its physiological system development and function were embryonic development, nervous system development and function, organ development; the relative disease and bio-functions' result are shown in Figure 3C and D. Two major interaction networks were identified (Table 3). The developmental disorder, ophthalmic disease, and organismal injury and abnormalities-related network was the highest scoring network with 18 identified proteins out of a possible 36 molecules associated with the network (Figure 4). This was followed with embryonic development, nervous system development and function, and organ development, with four identified proteins out of 35 molecules associated with the network. The snapshot (Figure 5) shows the interactions found in the query data; we constructed a network of 18 proteins.

\section{Discussion}

Very few therapies have been shown to cure or prevent cataracts effectively, with the only effective treatment being surgery. ${ }^{20}$ Though cataract surgery is recognized as being safe

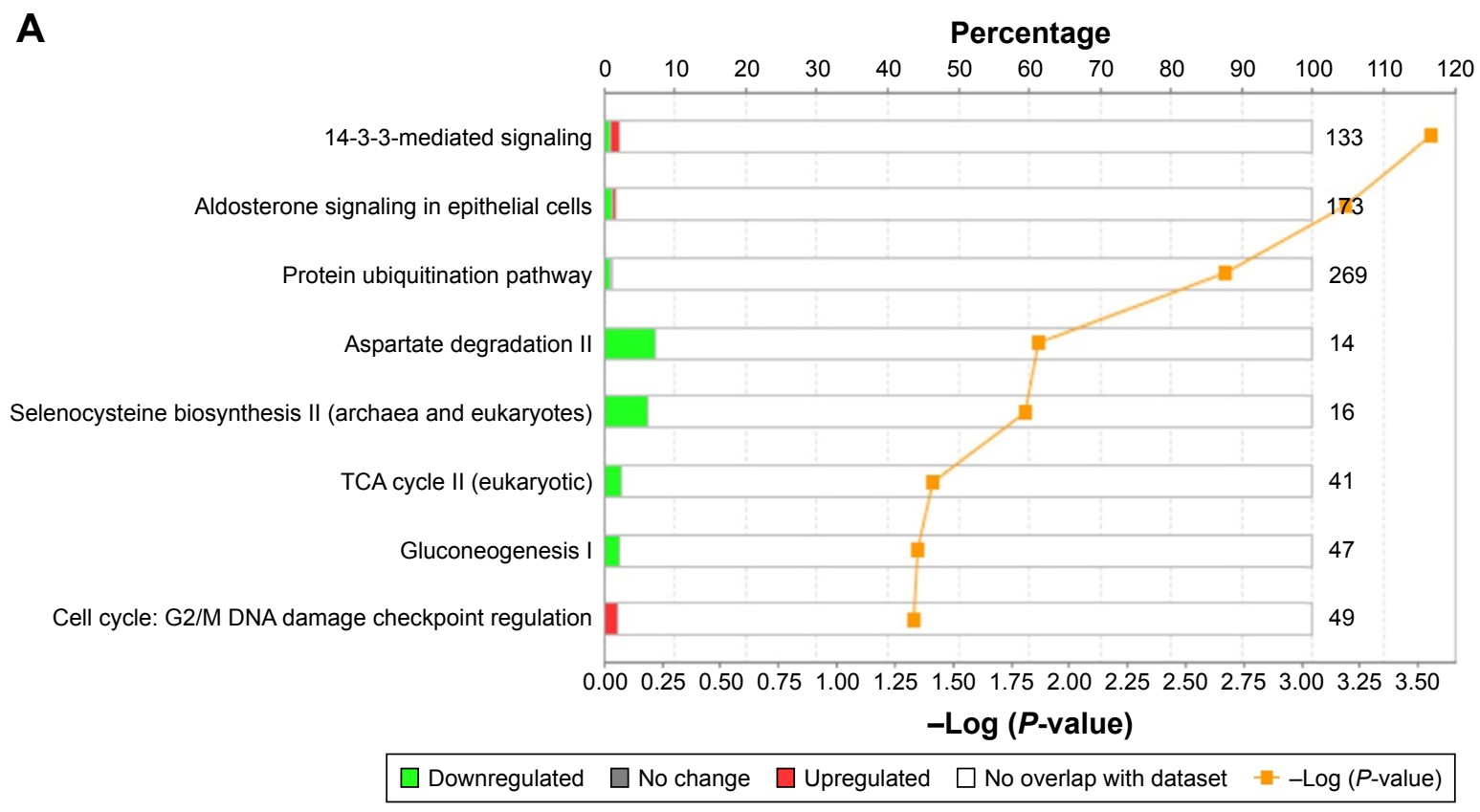

B

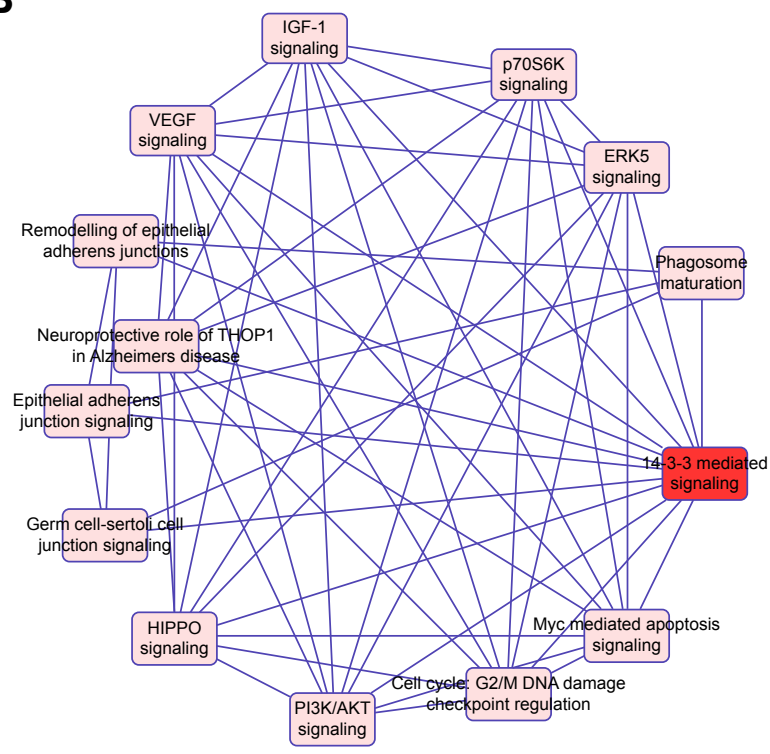

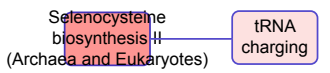
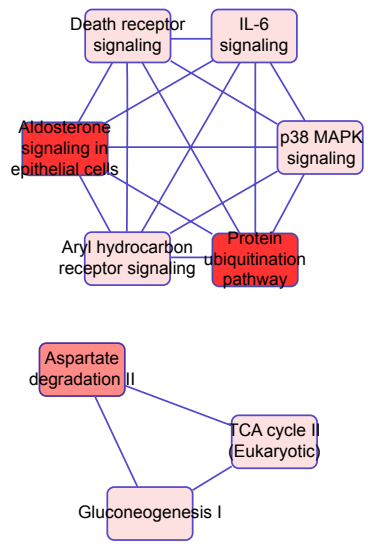

Figure 3 (Continued) 


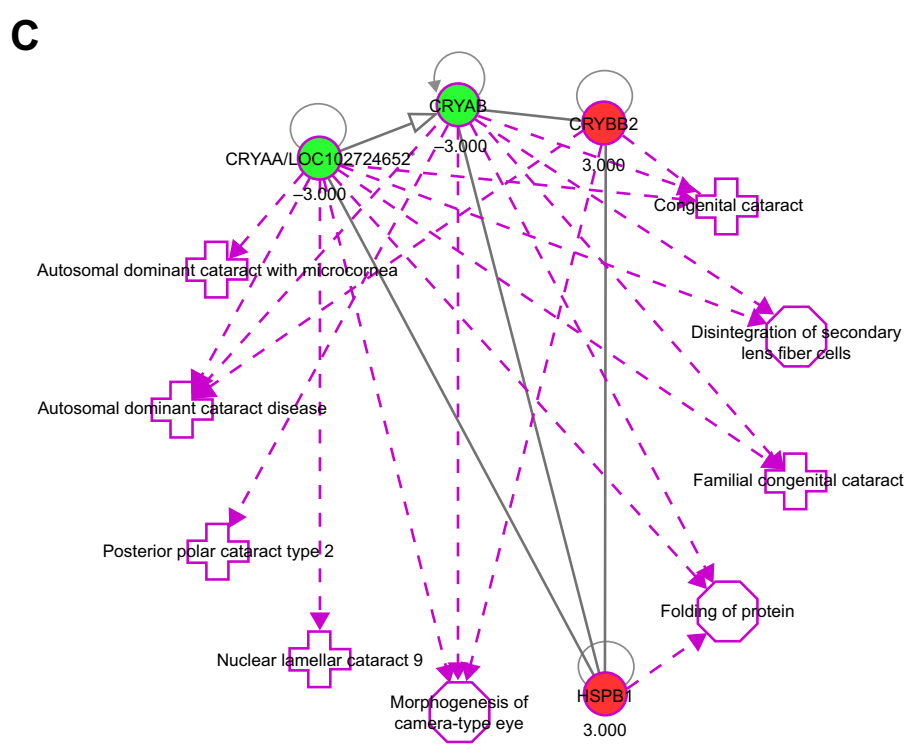

D

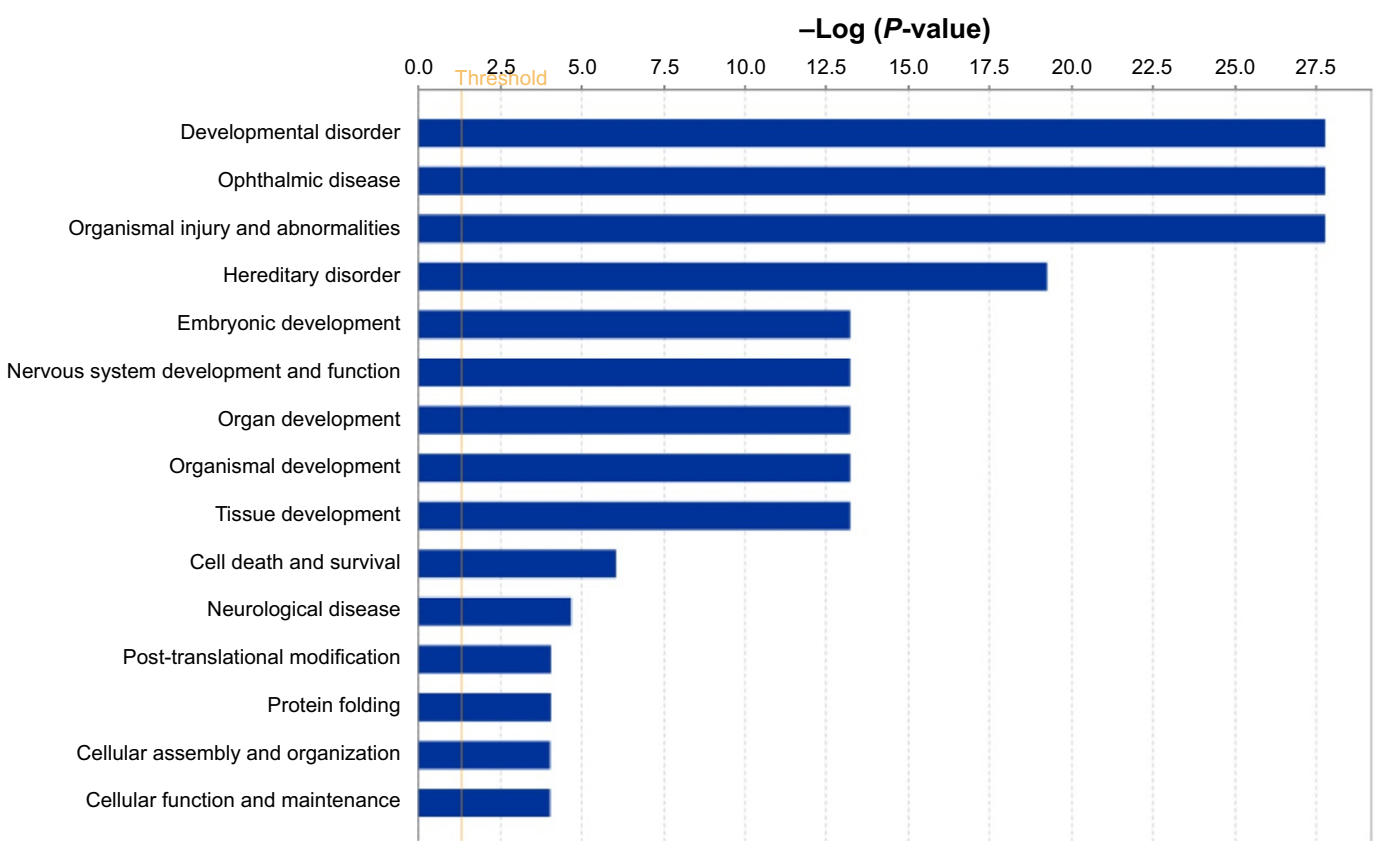

Figure 3 Ingenuity pathways' analysis of expression proteins.

Notes: (A) Top canonical pathways identified by IPA that are searched of lens proteins. (B) IPA reveals a network of signaling pathways searched by lens proteins. (C) The biologically active functions' network of main lens proteins. (D) The biological functions of lens proteins.

Abbreviation: IPA, Ingenuity Pathway Analysis.

with a high success rate, there is a significant rate of complications leading to irreversible blindness. Its affordability, acceptability, and accessibility are also limited. It is therefore relevant and important to look for alternative pharmacological measures for treating this disorder. Exploring the mechanisms of cataractogenesis and applying pharmacological interventions are crucial steps required to inhibit or delay lens opacification. Thus, we decide to explore a dosage form of a natural compound with a potent anti-cataract effect.
Ten to fourteen day old suckling rats were single subinjected once with sodium selenite $19-30 \mu \mathrm{mol} / \mathrm{kg}$ body weight, and then, selenite cataract was produced within 4-6 days. Selenite causes nuclear opacity by inducing oxidative stress in lens tissue. Similar to age-related cataract, several biochemical processes such as altered epithelial metabolism, calcium accumulation, crystalline precipitation, and cytoskeletal loss occur during the development of selenite-induced cataract. It is generally accepted that 
Table 3 The cataract-related protein networks

\begin{tabular}{|c|c|c|c|c|}
\hline ID & Molecules in network & Score & $\begin{array}{l}\text { Focus } \\
\text { molecules }\end{array}$ & Top functions \\
\hline 1 & 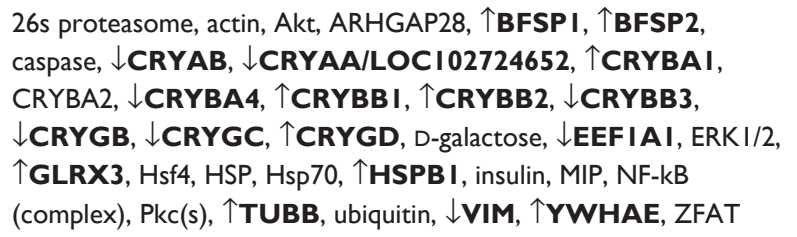 & 51 & $18 / 36$ & $\begin{array}{l}\text { Developmental disorder, } \\
\text { ophthalmic disease, } \\
\text { organismal injury and } \\
\text { abnormalities }\end{array}$ \\
\hline 2 & $\begin{array}{l}\text { ARIH2, CARS, CLIC4, CNN3, } \downarrow \text { CRYGA, } \downarrow \text { Cryge/Crygf, EIF5, } \\
\text { EIF4G2, EIF4G3, HSF4, IPO9, MAF, MAFG, } \downarrow \text { MDHI, MDH2, MTBP, } \\
\text { NTRKI, NUAKI, PAFAHIB3, PIK3R4, PPAI, PPMIF, PROXI, } \\
\text { RGSI2, RNF40, } \downarrow \text { SARS, TAFIA, THOPI, Top2, TP53, TWIST2, } \\
\text { UPPI, USPI4, VPS8, VPS33A }\end{array}$ & 8 & $4 / 35$ & $\begin{array}{l}\text { Embryonic development, } \\
\text { nervous system } \\
\text { development and function, } \\
\text { organ development }\end{array}$ \\
\hline
\end{tabular}

Note: Bold text= protein which was found in our experiment, we can see it was upregulated or downregulated.

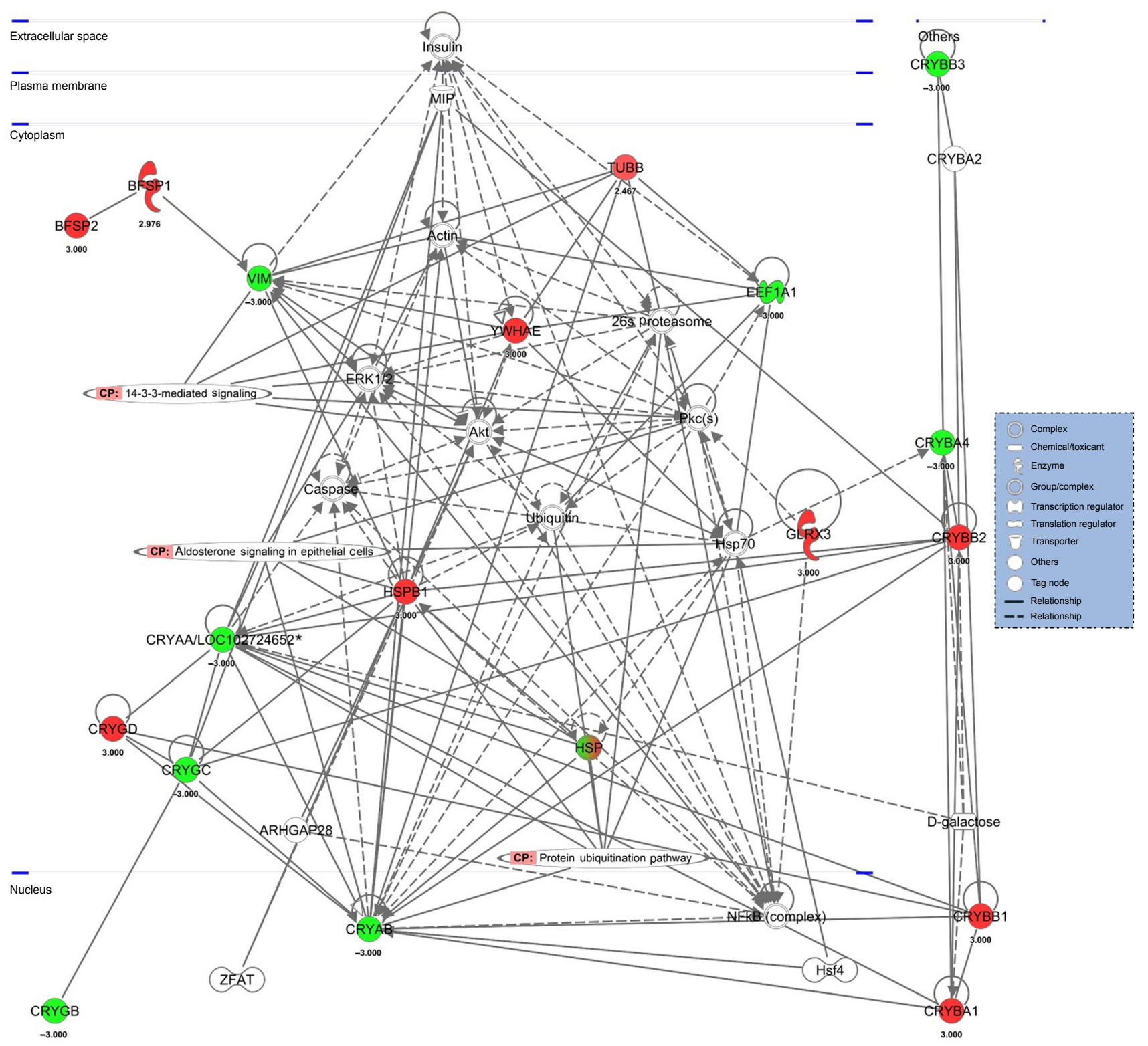

Figure 4 Functional pathway analysis using the IPA database.

Notes: The network indicates the interaction network among differentially expressed proteins. Nodes show genes or gene products. A direct relation between nodes is demonstrated by solid lines, and an indirect relation between nodes is demonstrated by dashed lines. 


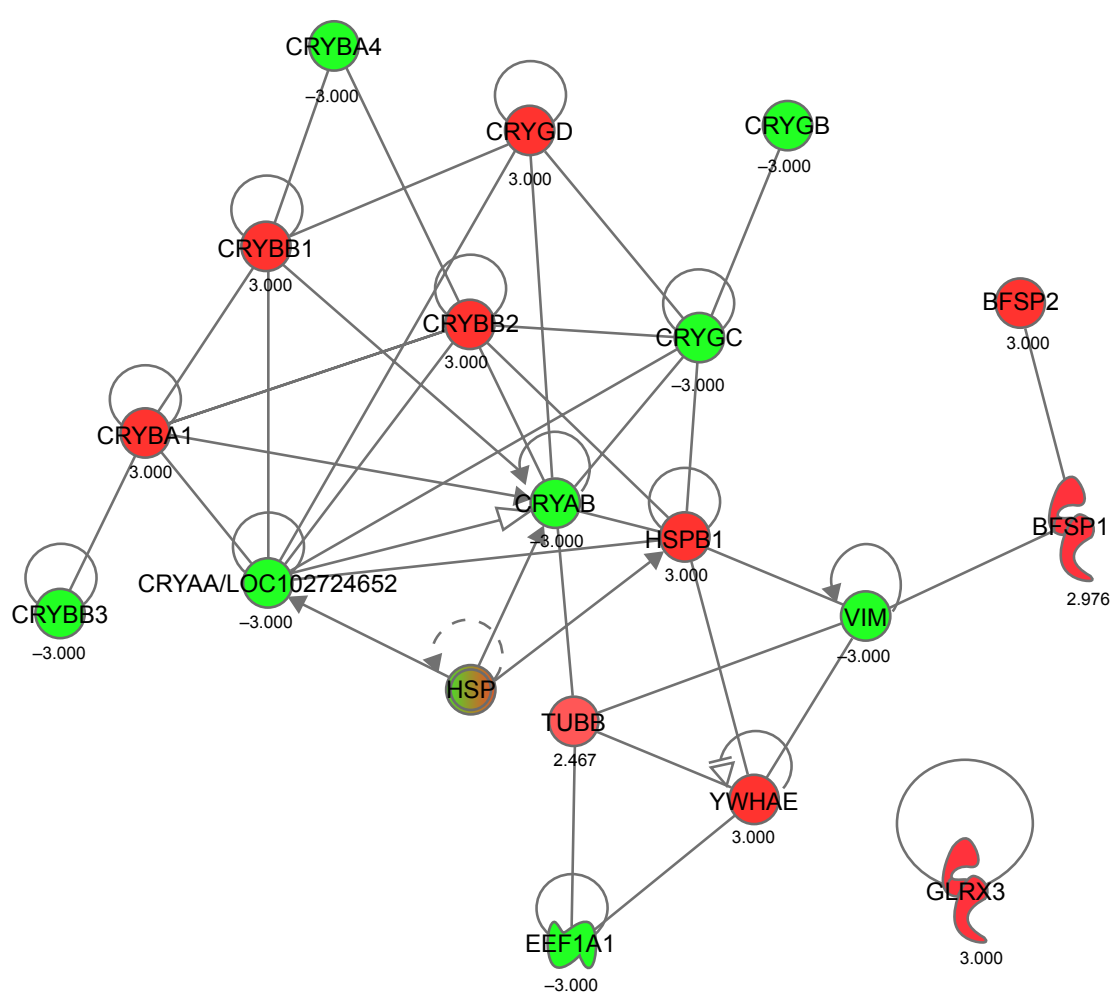

Figure 5 Direct interactions found in query data in string database.

selenite administration results in hydrogen peroxide formation, lipid peroxidation, decrease in activities of the antioxidant enzymes such as SOD, and reduced GSH levels. ${ }^{21}$ Results from a previous study showed that the activities of SOD and GSH were significantly higher in BA-SLN-treated cataract group compared to the nontreated group. ${ }^{11} \mathrm{BA}-\mathrm{SLNs}$ therefore protect the lens from oxidant damage due to toxic chemicals. In this study, morphological cataract staging was used to evaluate the morphological effects of BA-SLNs. The result suggests that BA-SLNs play an important role in delaying the onset and progression of cataract.

2D-PAGE, which provides high resolution of complex protein mixtures, was used in this study to separate proteins. Definitive protein identification has traditionally been conducted by nano-LC-MS/MS, and thus, this conventional method was also applied. These methods have become the main and preferred techniques in proteomics research. ${ }^{22}$ A total of 23 proteins have been identified from the 65 differentially expressed proteins. Of these, 12 proteins were upregulated and 11 proteins were downregulated in sodium selenite-induced rat lens. However, many proteins were not identified. Reasons may be as follows: first, the proteins of rat pups' lenses are incomplete as the lenses are still growing and as such many of these proteins are absent in the database and, second, the identification of an individual protein is related to the present individual protein's abundance in the lens. As such, some trace proteins have not been detected by this procedure.

To better understand the biological context and involvement in diverse pathways of the sodium selenite-induced differentially expressed proteins in rat lens, we performed functional pathway analysis using the ingenuity pathway analysis (IPA) database. The core analysis with the IPA software to the canonical pathway indicated that the target proteins of model and BA-SLNs genes were involved with pathways of 14-3-3-mediated signaling, aldosterone signaling in epithelial cells, etc. 14-3-3-Mediated signaling is mostly related to apoptosis and cell cycle regulation including VIM, TUBB, and YWHAE of these 23 differentially expressed proteins.

Vimentin encodes a member of the intermediate filament family. Intermediate filaments, along with microtubules and actin microfilaments, make up the cytoskeleton. The protein encoded by this gene is responsible for maintaining cell shape and integrity of the cytoplasm and stabilizing cytoskeletal interactions. Mutations in this gene cause a dominant, pulverulent cataract. ${ }^{23}$ TUBB encodes a beta-tubulin protein. It forms a dimer with alpha-tubulin and acts as a structural component of microtubules. YWHAE product belongs to the 14-3-3 family of proteins, which mediate signal transduction by binding to phosphoserine-containing proteins. 
Aldosterone signaling in epithelial cells is a nuclear receptor signaling. It includes CRYAA/LOC102724652, CRYAB, and HSPB1. Mammalian lens crystallins are divided into alpha, beta, and gamma families. Alpha crystallins are composed of two gene products, such as alpha-A and alpha-B, for acidic and basic, respectively. Alpha crystallins can be induced by heat shock and are members of the small heat shock protein (sHSP; HSP20) family. Two additional functions of alpha crystallins are an autokinase activity and participation in the intracellular architecture. The encoded protein has been identified as a moonlighting protein based on its ability to perform mechanistically distinct functions. Alpha-A and alpha-B gene products are differentially expressed; alpha-A is preferentially restricted to the lens and alpha-B is expressed widely in many tissues and organs. Defects in this gene cause autosomal dominant congenital cataract (ADCC). Elevated expression of alpha-B crystallin occurs in many neurological diseases. The protein encoded by HSPB1 is induced by environmental stress and developmental changes. The encoded protein is involved in stress resistance and actin organization and translocates from the cytoplasm to the nucleus upon stress induction. Protein ubiquitination pathway is an intracellular and second messenger signaling. It also includes CRYAA/LOC102724652, CRYAB, and HSPB1. Protein-protein interactions (PPIs) play crucial roles in every biological process. ${ }^{24-26}$ Protein interaction networks are represented by nodes and edges where nodes represent proteins while edges represent interactions between proteins..$^{27,28}$ Figure 5 represents the conjunctions of protein, which means that the higher the connection, the more important the protein is. A previous study reported that proteins with the highest number of interactions are the most essential proteins for survival. ${ }^{29} \mathrm{CRYAB}$, the highest connected protein, had relations with an other nine proteins. CRYAA related with an other eight proteins. HSPB1 had relations with an other seven proteins, indicating that CRYAB, CRYAA, and HSPB1 might play very important roles in the whole network. Previous studies have shown that sHSPs belong to molecular chaperones, which are essential elements in cellular protection. ${ }^{30-32}$ By forming stable complexes with folding or unfolding intermediate protein substrates, probably the molten globule, the sHSPs (which include alpha crystallin) can form large multimeric structures and have a wide range of cellular functions, including endowing cells with thermotolerance in vivo and being able to act as molecular chaperones in vitro. ${ }^{33,34}$ Among them, HSPB1, HSPB4, and HSPB5 are responsible for the development of cataract, oncogenesis, and antiapoptotic activity. ${ }^{35-37}$ The lens is largely formed from $\alpha$-crystallin and $\beta \gamma$-crystallin superfamily with the main cellular partners of $\alpha-, \beta$-, and $\gamma$-crystallin being abundant in vertebrate eye lens. ${ }^{38}$ Besides transparency, the major role of the partnership of $\alpha$-crystallin with $\beta$ - and $\gamma$-crystallin in the lens is to form a refractive index gradient. ${ }^{39-41}$ As many studies showed, the $\alpha$-crystallin is an evolutionarily related group of sHSPs that play a role in producing and maintaining the transparency and refractive power of the vertebrate's ocular lens. ${ }^{42-44}$ Under various stresses, the inducibility of HSPs and $\alpha$-crystallin transcription is exerted by HSF-dependent mechanisms, by which concomitant induction of HSPs and $\alpha$-crystallin expression is observed. ${ }^{45,46}$ Functional changes in $\alpha$-crystallin have been shown to modify membrane and cell-cell interactions and lead to lens cell pathology in vivo. ${ }^{47-49}$ Therefore, these proteins are potential therapeutic targets in many diseases. This study also provided other proteins as candidates that play a role in the lens. However, further experimental validation is needed to demonstrate the molecule mechanism in cataract. This study can lead to the development of new treatment for cataract.

\section{Conclusion}

In present study, we used sodium selenite-induced cataract rat model to look into the lens transparency in response to BA-SLNs' treatment for the first time, which indicated that BA-SLNs play an important role in delaying the onset and progression of cataract. 2D-PEGA combined with the highly sensitive nano-LC-MS/MS method was employed to analyze the differential proteomic profile of the lens. A total of 23 proteins were identified by this proteomics analysis among the differentially expressed proteins, appearing to be implicated in the progression of cataract formation. Bioinformatic analysis was employed to better understand the identified proteins including classification by biological process, cellular component, molecular function and construction of pathways, and PPIs' network analysis, which would be significant to the study of the lens proteins of rat in the future. This study could serve as a basis for further clinical investigations.

\section{Acknowledgments}

We gratefully acknowledge Lie Bo Su of Proteomic Technology Service Center, Bo Yuan (Shanghai) Biological Technology Co., Ltd, and Huan Zhao of Analytical Testing Center, Tianjin International Joint Academy of Biotechnology and Medicine, for technical assistance with data collection and analysis. We would also like to acknowledge Dr Hao 
Wang of Tianjin Biochip Corporation for the technical assistance with the experiment.

\section{Disclosure}

The authors report no conflicts of interest in this work.

\section{References}

1. Congdon N, Vingerling JR, Klein BE, et al. Prevalence of cataract and pseudophakia/aphakia among adults in the United States. Arch Ophthalmol. 2004;122(4):487-494.

2. Kothadia AD, Shenoy AM, Shabaraya AR, Rajan MS, Viradia UM, Patel NH. Evaluation of cataract preventive action of phycocyanin. Int J Pharm Sci Drug Res. 2011;3(1):42-44.

3. Truscott RJ. Age-related nuclear cataract-oxidation is the key. Exp Eye Res. 2005;80(5):709.

4. Green K. Free radicals and aging of anterior segment tissues of the eye: a hypothesis. Ophthalmic Res. 1995;27(suppl 1):143-149.

5. Shearer TR, Ma H, Fukiage C, et al. Selenite nuclear cataract: Review of the model. Molecular Vision. 1997;3(3):8-20.

6. Awasthi S, Srivatava SK, Piper JT, Singhal SS, Chaubey M, Awasthi YC. Curcumin protects against 4-hydroxy-2-trans-nonenal-induced cataract formation in rat lenses. Am J Clin Nutr. 1996;64(5):761.

7. Durukan AH, Evereklioglu C, Hurmeric V, et al. Ingestion of IH636 grape seed proanthocyanidin extract to prevent selenite-induced oxidative stress in experimental cataract. J Cataract Refract Surg. 2006; 32(6): 1041-1045.

8. Patel DK, Kumar R, Prasad SK, Hemalatha S. Pedalium murex Linn (Pedaliaceae) fruits: a comparative antioxidant activity of its different fractions. Asian Pac J Trop Biomed. 2011;1(5):395-400.

9. Cavalli R, Gasco MR, Chetoni P, Burgalassi S, Saettone MF. Solid lipid nanoparticles (SLN) as ocular delivery system for tobramycin. Int J Pharm. 2002;238(1-2):241-245.

10. Liu Z, Zhang X, Wu H, et al. Preparation and evaluation of solid lipid nanoparticles of baicalin for ocular drug delivery system in vitro and in vivo. Drug Dev Ind Pharm. 2011;37(4):475.

11. Han ZZ, Nan LI, Guo LL, Tong L, Chen J. Preventive effect of two ophthalmic preparations of baicalin against selenium cataract. J Tianjin Univ Tradit Chin Med. 2014;(3):40-43.

12. Zhao Y, Li H, Gao Z, Xu H. Effects of dietary baicalin supplementation on iron overload-induced mouse liver oxidative injury. Eur J Pharmacol. 2005;509(2-3):195.

13. Yates JR 3rd, Gilchrist A, Howell KE, Bergeron JJ. Proteomics of organelles and large cellular structures. Nat Rev Mol Cell Biol. 2005;6(9): $702-714$.

14. Andersen JS, Mann M. Organellar proteomics: turning inventories into insights. EMBO Rep. 2006;7(9):874.

15. Schmidt A, Aebersold R. High-accuracy proteome maps of human body fluids. Genome Biol. 2006;7(11):242.

16. Hains P, Truscott R. Proteomic analysis of the oxidation of cysteine residues in human age-related nuclear cataract lenses. Biochim Biophys Acta. 2008;1784(12):1959-1964.

17. Bennett KL, Funk M, Tschernutter M, et al. Proteomic analysis of human cataract aqueous humour: comparison of one-dimensional gel LCMS with two-dimensional LCMS of unlabelled and iTRAQ ${ }^{\circledR}$-labelled specimens. J Proteomics. 2011;74(2):151-166.

18. Elanchezhian R, Sakthivel M, Geraldine P, Thomas PA. The effect of acetyl-L-carnitine on lenticular calpain activity in prevention of selenite-induced cataractogenesis. Exp Eye Res. 2009;88(5):938.

19. Hiraoka T, Clark JI. Inhibition of lens opacification during the early stages of cataract formation. Invest Ophthalmol Vis Sci. 1995; 36(12):2550.

20. Javadzadeh A, Ghorbanihaghjo A, Bonyadi S, et al. Preventive effect of onion juice on selenite-induced experimental cataract. Indian $J$ Ophthalmol. 2009;57(3):185.
21. David LL, Shearer TR. State of sulfhydryl in selenite cataract. Toxicol Appl Pharmacol. 1984;74(1):109-115.

22. Görg A, Obermaier C, Wildgruber R, et al. The current state of twodimensional electrophoresis with immobilized $\mathrm{pH}$ gradients Proteomics and 2-DE. Electrophoresis. 2000;21(6):1037-1053.

23. Weisburg WG, Lidgard GP, Ahlquist DA, et al. Marker Panel for Detecting Cancer. US, WIPO Patent Application WO/2013/ $142545[\mathrm{P}]$.

24. Lee SA, Chan $\mathrm{CH}$, Chen TC, et al. POINeT: protein interactome with sub-network analysis and hub prioritization. BMC Bioinformatics. 2009; 10(1):114

25. Casadovela J, Fuentes M, Francozorrilla JM. Screening of proteinprotein and protein-DNA interactions using microarrays: applications in biomedicine. Adv Protein Chem Struct Biol. 2014;95:231-281.

26. Murakami Y, Mizuguchi K. Homology-based prediction of interactions between proteins using Averaged One-Dependence Estimators. BMC Bioinformatics. 2014;15(1):1-11.

27. Yegerlotem E, Sattath S, Kashtan N, et al. Network motifs in integrated cellular networks of transcription-regulation and protein-protein interaction. Proc Natl Acad Sci U S A. 2004;101(16):5934-5939.

28. Ghosh A, Brinda KV, Vishveshwara S. Dynamics of lysozyme structure network: probing the process of unfolding. Biophys J. 2007;92(7): 2523-2535.

29. Jeong H, Mason SP, Barabási AL, Oltvai ZN. Lethality and centrality in protein networks. Nature. 2001;411(6833):41.

30. Laskowska E. [Small heat shock proteins - role in apoptosis, cancerogenesis and diseases associated with protein aggregation]. Postepy Biochem. 2007;53(1):19-26.

31. Kim R, Kim KK, Yokota H, Kim SH. Small heat shock protein of Methanococcus jannaschii, a hyperthermophile. Proc Natl Acad Sci U S A. 1998;95(16):9129-9133.

32. Scieglinska D, Piglowski W, Chekan M, Mazurek A, Krawczyk Z. Differential expression of HSPA1 and HSPA2 proteins in human tissues; tissue microarray-based immunohistochemical study. Histochem Cell Biol. 2011;135(4):337.

33. Klein RD, Chidawanyika T, Tims HS, Meulia T, Bouchard RA, Pett VB. Chaperone function of two small heat shock proteins from maize. Plant Sci. 2014;221-222:48-58.

34. BashaE, Jones C, Wysocki V, Vierling E. Mechanistic differences between two conserved classes of small heat shock proteins found in the plant cytosol. J Biol Chem. 2010;285(15):11489.

35. Arrigo A, Gibert B. HspB1, HspB5 and HspB4 in human cancers: potent oncogenic role of some of their client proteins. Cancers (Basel). 2014; 6(1):333-365.

36. Skouri-Panet F, Michiel M, Férard C, Duprat E, Finet S. Structural and functional specificity of small heat shock protein HspB1 and HspB4, two cellular partners of HspB5: role of the in vitro hetero-complex formation in chaperone activity. Biochimie. 2012;94(4):975-984.

37. Arrigo AP, Gibert B. Protein interactomes of three stress inducible small heat shock proteins: HspB1, HspB5 and HspB8. Int J Hyperthermia. 2013;29(5):409-422.

38. Wistow G. The human crystallin gene families. Hum Genomics. 2012; 6(1):1-10.

39. Slingsby C, Wistow GJ, Clark AR. Evolution of crystallins for a role in the vertebrate eye lens. Protein Sci. 2013;22(4):367.

40. Andley UP. Crystallins in the eye: function and pathology. Prog Retin Eye Res. 2007;26(1):78-98.

41. Wang X, Garcia CM, Shui YB, Beebe DC. Expression and regulation of $\alpha-, \beta$-, and $\gamma$-crystallins in mammalian lens epithelial cells. Invest Ophthalmol Vis Sci. 2004;45(10):3608-3619.

42. Pasupulati AK, Geereddy BR. Modulation of $\alpha$-crystallin chaperone activity: a target to prevent or delay cataract? IUBMB Life. 2009;61(5): 485-495.

43. Christopher KL, Pedler MG, Shieh B, Ammar DA, Petrash JM, Mueller NH. Alpha-crystallin-mediated protection of lens cells against heat and oxidative stress-induced cell death. Biochim Biophys Acta. 2014;1843(2):309. 
44. Horwitz J. The function of alpha-crystallin in vision. Seminars in Cell and Developmental Biology. 2000;11(1):53-60.

45. Acunzo J, Katsogiannou M, Rocchi P. Small heat shock proteins HSP27 (HspB1), $\alpha$ B-crystallin (HspB5) and HSP22 (HspB8) as regulators of cell death. Int J Biochem Cell Biol. 2012;44(10):1622-1631.

46. Clark AR, Lubsen NH, Slingsby C. sHSP in the eye lens: crystallin mutations, cataract and proteostasis. Int J Biochem Cell Biol. 2012; 44(10):1687-1697.

47. Andley UP. Effects of alpha-crystallin on lens cell function and cataract pathology. Curr Mol Med. 2009;9(7):887-892.

48. Hwang KH, Lee EH, Jho EH, et al. Accumulation and aberrant modifications of alpha-crystallins in anterior polar cataracts. Yonsei Med J. 2004;45(1):73.

49. Graw J. Genetics of crystallins: cataract and beyond. Exp Eye Res. 2009;88(2):173.
50. Cheng K, Wu Z, Gao B, Xu J. Analysis of Influence of Baicalin Joint Resveratrol Retention Enema on the TNF- $\alpha$, SIgA, IL-2, IFN- $\gamma$ of Rats with Respiratory Syncytial Virus Infection. Cell Biochemistry \& Biophysics. 2014;70(2):1305.

51. Wang G, Liang J, Gao L, et al. Baicalin administration attenuates hyperglycemia-induced malformation of cardiovascular system. Cell Death Dis. 2018;9(2):234.

52. Fu S, Liu H, Lei X, et al. Baicalin modulates NF- $\kappa B$ and NLRP3 inflammasome signaling in porcine aortic vascular endothelial cells Infected by Haemophilus parasuis Causing Glässer's disease. Sci Rep-Uk. 2018;8(1).

\section{Publish your work in this journal}

Drug Design, Development and Therapy is an international, peerreviewed open-access journal that spans the spectrum of drug design and development through to clinical applications. Clinical outcomes, patient safety, and programs for the development and effective, safe, and sustained use of medicines are the features of the journal, which has also been accepted for indexing on PubMed Central. The manuscript management system is completely online and includes a very quick and fair peer-review system, which is all easy to use. Visit http://www.dovepress.com/testimonials.php to read real quotes from published authors.

Submit your manuscript here: http://www.dovepress.com/drug-design-development-and-therapy-journal 